Article

\title{
Fault Ride-Through Characteristics of Small Wind Turbines
}

\author{
Junji Kondoh *, Hidetoshi Mizuno and Takuji Funamoto \\ Department of Electrical Engineering, Graduate School of Science and Technology, Tokyo University of Science, \\ Chiba 278-8510, Japan; mizu.march@gmail.com (H.M.); gg.pstank@gmail.com (T.F.) \\ * Correspondence: j.kondoh@rs.tus.ac.jp; Tel.: +81-4-7122-9521
}

Received: 3 October 2019; Accepted: 27 November 2019; Published: 2 December 2019

\begin{abstract}
There is significant potential for an increase in the use of kilowatt-class small wind turbines (SWTs) in Japan due to reduced limitations with respect to installation, despite their high cost. At this stage, the Japanese grid code has not been considered sufficiently with respect to grid-connected SWTs, and the addition of fault ride-through (FRT) requirements for SWTs has been requested. Moreover, the FRT of SWTs is challenging to achieve owing to the low inertia constants when compared with those of large-scale wind turbines, which result in significant acceleration of the rotor speed and an increase in the input voltage of the power conditioning system (PCS) during FRT operation. In this study, FRT field tests were conducted on SWT systems against a voltage dip with a duration of $\sim 1$ $\mathrm{s}$, and it was confirmed that the SWT systems satisfied the FRT requirements for photovoltaic (PV) systems connected to low-voltage distribution lines in Japan. The behaviors of the rotational speed of the SWTs and the PCS input voltage in an FRT operation were then analyzed, and it was noted that the increase in the PCS input voltage with the overspeed of the turbine can reach the upper limit and make the PCS cease operation, which indicates failure of the FRT. The overvoltage, therefore, requires restriction using a method such as pitch control, furling, and electrical and/or mechanical brakes.
\end{abstract}

Keywords: fault ride-through; small wind turbine; inertia; power conditioning system (PCS); over speed

\section{Introduction}

In recent years, there has been a significant increase in the installation of grid-connected dispersed generators. In several areas in Japan, an excessive number of photovoltaic (PV) power systems have been installed. This has resulted in significant variation of the net-load shape with the evening peak and afternoon bottom, which is referred to as the "Duck Curve" [1,2]. One method that reduces the impact of the "Duck Curve" involves an increase in the penetration ratio of other renewable energy resources with different generation power profiles, such as wind power. Although megawatt-class large-scale wind turbines have been widely installed worldwide owing to their competitive prices, the development of wind turbines in Japan has been gradual because of unclear and inconsistent policies, in addition to the lengthy process required for assessment of their environmental impact [3,4]. In contrast, the use of kilowatt-class small-scale wind turbines (SWTs) can potentially increase in Japan because of reduced limitations with respect to installation; however, their high initial cost is a bottleneck. In addition, the application procedures for connecting SWTs to the grid are currently time-consuming and costly, owing to the lack of a type certification system for the grid code compliance of the power conditioning systems (PCSs) of SWTs in Japan. Because the existing conditions increase the labor cost of both utilities and manufacturers of SWTs, the development of a type certification system and the revision of the grid code are under consideration. In this discussion, the fault ride-through (FRT) requirements for SWTs are of great concern. 
The FRT requirements specify that wind turbines should remain connected to the grid to prevent the mass drop of the power supply when an abnormal grid voltage and/or frequency with a short duration is detected. In Japan, the FRT requirements are imposed on PV power systems for all voltage levels, in addition to large-scale wind turbines [5]. Thus, Japanese utilities suggest the imposition of similar FRT requirements on SWTs for equality.

When a voltage dip occurs at the alternating current (AC) output terminals, the maximum active power that the generation system can output is reduced in proportion to the terminal voltage reduction. In the case of the PV power system, treatment of excess energy is not a concern because the input power can be decreased simultaneously (up to zero, if necessary) with an increase in the PV array voltage (up to a maximum of the open-circuit voltage) by the control of a power electronic interface, such as a direct current (DC)-DC converter [6]. However, in the case of the wind power system, the input power extracted from the wind turbine blades cannot be rapidly reduced, given that any factor, such as the pitch angle, needs to be mechanically controlled [7]. This results in an imbalance between the input and output power of the wind turbine, which leads to an increase in the rotational speed. If SWTs use doubly fed induction generators (DFIGs), advanced control strategies could become available to restrict over-voltage without such extra hardware as dump resistors [8,9]. However, DFIGs are rarely used on SWTS, and many SWTs use permanent magnet synchronous generators (PMSGs) [10], in which overspeed directly leads to excessive terminal voltage.

In the case of a large-scale WT system equipped with a PMSG and a full-scale frequency converter, which is a configuration similar to that of many SWT systems, a dump resistor is employed to dissipate the excess energy in the DC-link circuit [7,11]. In contrast, it is difficult to employ dump resistors in the PCSs for SWTs owing to commercial issues, i.e., the PCSs have the same hardware as the $\mathrm{kW}$-class PCSs for the residential PV systems. Instead, PCS manufacturers are opposed to costly modification of the hardware and insist that the SWT side should dissipate excess energy before the input to the PCSs so as to satisfy the FRT requirements. In particular, more significant increases were expected for SWTs, owing to their generally low inertia constants; furthermore, several have no mechanism for the pitch control. Consequently, the FRT of SWTs is challenging to achieve, although the FRT of large-scale wind turbines has already been developed. To further discuss the type certification system and grid code, it is important to understand the behaviors of the rotational speed of the SWTs and the PCS input voltage of such SWT systems equipped with commercial PCSs during short-term grid faults, and to confirm that the PCSs satisfy the FRT requirements under drastic variation of the input voltage. In this study, FRT field tests were conducted on SWT systems to investigate their behaviors, and the results were analyzed.

The remainder of this paper is organized as follows. Section 2 describes the typical configuration of a grid-connected SWT system and the mechanism of the control and variation of the rotational speed of the SWT. Section 3 gives the specification and configuration of the 5-kW SWT system and the FRT test system and analyzes the test results. Section 4 describes the FRT test result for the other system with two 1-kW SWTs. Finally, Section 5 presents concluding remarks.

\section{Grid-Connected SWT}

\subsection{Typical Configuration}

In general, a grid-connected SWT system has a DC-link circuit, i.e., the AC output power of a permanent magnet synchronous generator is converted to DC power by a rectifier, and then to AC power by matching the voltage and phase conditions of the electricity grid using a power conditioning system (PCS); as shown in Figure 1. In Japan, to reduce the cost, the PCSs of the SWTs have the same hardware as the kW-class PCSs for mass-produced residential PV power systems, which do not require excess energy treatment for FRT. In other words, only the software for the maximum power point tracking (MPPT) algorithm of the DC-DC converter was modified. 


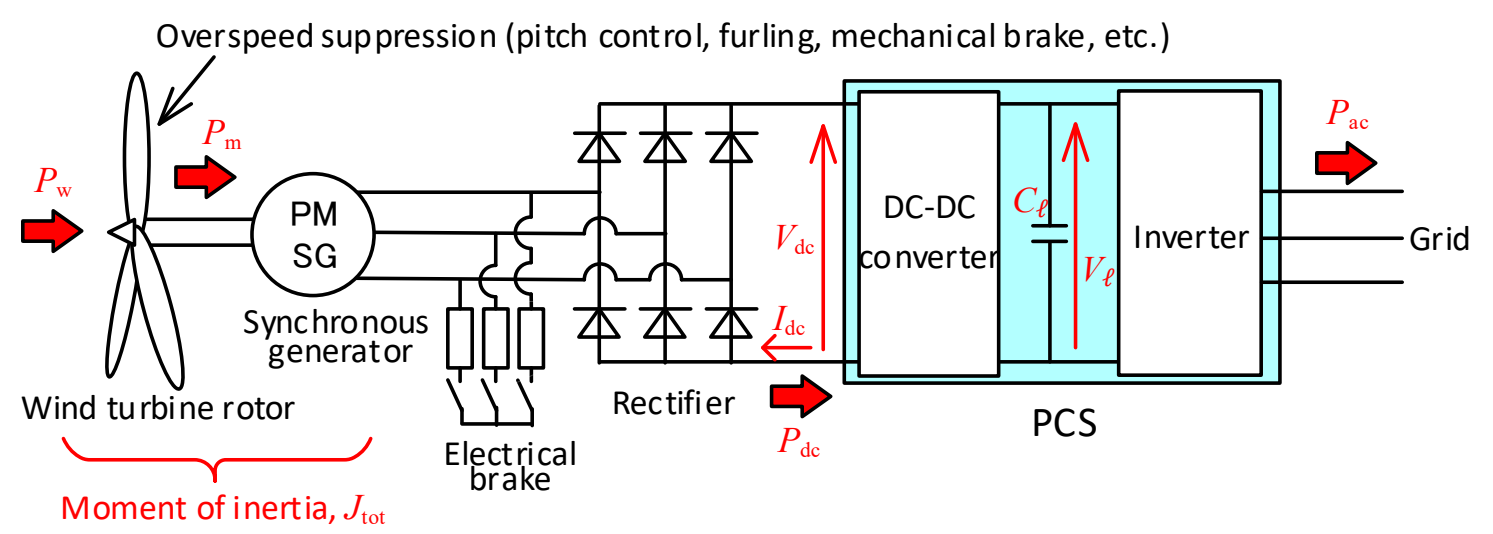

Figure 1. Typical configuration of a grid-connected small wind turbine system.

\subsection{Rotational Speed Control Under Normal Conditions}

The power $P_{\mathrm{w}}$ of the wind is proportional to the cube of the wind speed $v_{\mathrm{w}}$, and the ratio of the mechanical input power $P_{\mathrm{m}}$ that the wind turbine can output $\left(P_{\mathrm{m}} / P_{\mathrm{w}}\right)$ is referred to as the power coefficient $C_{p}$. When the pitch angle of the wind turbine blades is fixed or constant, the power coefficient $C_{p}$ can be expressed as a function of the tip speed ratio $\lambda$. In this paper, the definition of the tip speed ratio $\lambda$ is $R \omega_{\mathrm{m}} / v_{\mathrm{w}}$; where $R$ is the rotor radius, and $\omega_{\mathrm{m}}$ is the rotor angular velocity of the wind turbine. The power coefficient becomes the maximum value $C_{\text {pmax }}$ at a certain optimal tip speed ratio $\lambda_{\text {opt }}$. The wind power system can always operate at the highest efficiency if the turbine angular speed $\omega_{\mathrm{m}}$ is controlled in accordance to $\lambda_{\mathrm{opt}} v_{\mathrm{w}} / R$ with respect to changes in the wind speed $v_{\mathrm{w}}$. This type of operation is referred to as a variable speed operation and is adopted in most SWT systems to obtain the highest energy yield.

If the power losses in the generator and rectifier are ignored, the PCS input power $P_{\mathrm{dc}}$ is the same as $P_{\mathrm{m}}$ when the electrical brake is not closed. When the highest efficiency is realized, $P_{\mathrm{m}}=C_{\mathrm{pmax}} P_{\mathrm{w}} \propto$ $C_{\text {pmax }} v_{\mathrm{w}}^{3}=\left(C_{\mathrm{pmax}} R^{3} / \lambda_{\mathrm{opt}}^{3}\right) \omega_{\mathrm{m}}^{3}$. In addition, the PCS input voltage $V_{\mathrm{dc}}$ is proportional to $\omega_{\mathrm{m}}$ if the voltage drop inside the generator is neglected. Thus, the MPPT of an SWT system is conducted by controlling the PCS input power $P_{\mathrm{dc}}$ with respect to the input voltage $V_{\mathrm{dc}}$, as shown in Figure 2 . As can be seen from Figure 2, the PCS input power $P_{\mathrm{dc}}$ is maintained at the rated value $P_{\text {acrate }}$ even if the PCS input voltage $V_{\mathrm{dc}}$ is higher than $V_{\mathrm{dcrate}}$. Under these conditions, the mechanical input power $P_{\mathrm{m}}$ is higher than the PCS output voltage $P_{\mathrm{ac}}$, which results in an increase in the turbine angular velocity $\omega_{\mathrm{m}}$. Instead of using the PCS to restrict this overspeed, other methods, such as pitch control, furling, and implementation of electrical and/or mechanical brakes, should be employed. The commercial PCS for an SWT cannot dissipate excess energy because it has the same hardware as those for the residential PV power systems, as described above. If the power losses in the PCS are ignored, the PCS output power $P_{\mathrm{ac}}$ must always be the same as $P_{\mathrm{dc}}$. Otherwise, the DC-link voltage $V_{\ell}$ in the PCS will change owing to the energy charge/discharge on the DC-link capacitor $C_{\ell}$, even though $V_{\ell}$ should be maintained within a certain level suitable to output the proper AC waveform to the grid.

\subsection{Rotational Speed Variation at Transient Condition}

The equation that describes the dynamics of the turbine angular velocity $\omega_{\mathrm{m}}$ can be expressed as follows:

$$
J_{\mathrm{tot}} \omega_{\mathrm{m}} \frac{d \omega_{\mathrm{m}}}{d t}=P_{\mathrm{m}}-P_{\mathrm{dc}}=P_{\mathrm{m}}-P_{\mathrm{ac}}
$$

where $J_{\text {tot }}$ is the equivalent inertia of the wind turbine and PMSG rotor, which is referred to as the turbine shaft. In particular, the turbine angular velocity $\omega_{\mathrm{m}}$ does not change when the mechanical input power $P_{\mathrm{m}}$ and electrical output power $P_{\mathrm{ac}}$ are balanced. However the electrical output power $P_{\text {ac }}$ may be lower than $P_{\mathrm{m}}$ when the AC output voltage $V_{\text {ac }}$ of the PCS dips, given that the maximum output power that the PCS can output is proportional to $V_{\mathrm{ac}}$. In this case, the PCS stops the MPPT 
operation in Figure 2, which results in the condition $P_{\mathrm{m}}>P_{\mathrm{ac}}$. The commercial PCS does not treat this excess energy, because it has no dump resistor to restrict the increase of the DC-link voltage $V_{\ell}$, as described in Section 2.2. Thus, all of the excess energy is spent accelerating the turbine angular velocity $\omega_{\mathrm{m}}$, according to Equation (1). Therefore, the increase of not the DC-link voltage $V_{\ell}$ but the PCS input voltage $V_{\mathrm{dc}}$ is a great concern in the SWT system with PMSG. By substituting the inertia constant $H$ for $J_{\text {tot }}$, the following result is obtained:

$$
2 H \frac{\omega_{\mathrm{m}}}{\omega_{\text {mrate }}} \frac{d\left(\omega_{\mathrm{m}} / \omega_{\text {mrate }}\right)}{d t}=\frac{P_{\mathrm{m}}}{P_{\text {acrate }}}-\frac{P_{\mathrm{ac}}}{P_{\text {acrate }}}
$$

where $\omega_{\text {mrate }}$ is the turbine angular velocity with rated power output under normal conditions, $P_{\text {acrate }}\left(\equiv P_{\text {dcrate }}\right)$ is the rated output power, and $H \equiv J_{\text {tot }} \omega_{\text {mrate }}^{2} /\left(2 P_{\text {acrate }}\right)$, which describes the duration over which the generator can supply rated power from its stored kinetic energy. Equation (2) indicates that the acceleration in the ratio of the rotor angular velocity $\omega_{\mathrm{m}}$ is more significant when the inertia constant $H$ is lower.

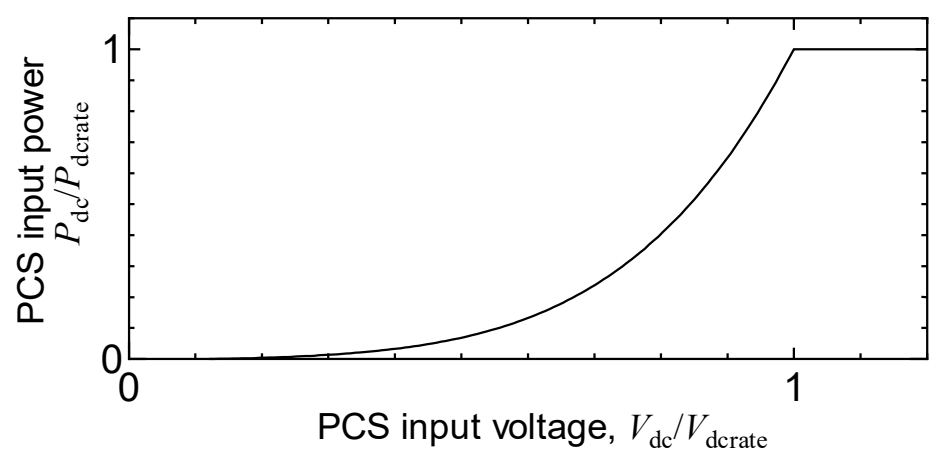

Figure 2. An example of the relationship between the power conditioning system (PCS) input voltage $V_{\mathrm{dc}}$ and input power $P_{\mathrm{dc}}$ for the maximum power point tracking (MPPT). The axes were normalized by $V_{\text {dcrate }}$ and $P_{\text {dcrate }}$ at the point at which the PCS input power reaches the rated value $P_{\text {dcrate }}$ when the input voltage is $V_{\text {dcrate }}$.

As listed in Table 1, the following parameters are related to the inertia constant $H$ of horizontal axis wind turbines (HAWTs): the rated output power $P_{\text {acrate, }}$ inertia of a wind turbine rotor $J_{\mathrm{wt}}$, inertia of a generator rotor $J_{\mathrm{g}}$, gear ratio $\eta$, number of generator pole pairs $p$, and frequency $f_{\text {erate }}$ of generator voltage with rated power output under normal conditions. The equivalent inertia of the wind turbine and the generator rotor referred to the turbine shaft is $J_{\mathrm{tot}}=J_{\mathrm{wt}}+\eta^{2} J_{\mathrm{g}}$. The rated angular velocity of the wind turbine rotor is then $\omega_{\text {mrate }}=2 \pi f_{\text {erate }} /(\eta p)$. Based on these equations, the inertia constant $H$ was calculated, as shown in Figure 3 and Table 1. Moreover, the following approximate relationship obtained from Equation (10) in [21] is also shown in Figure 3.

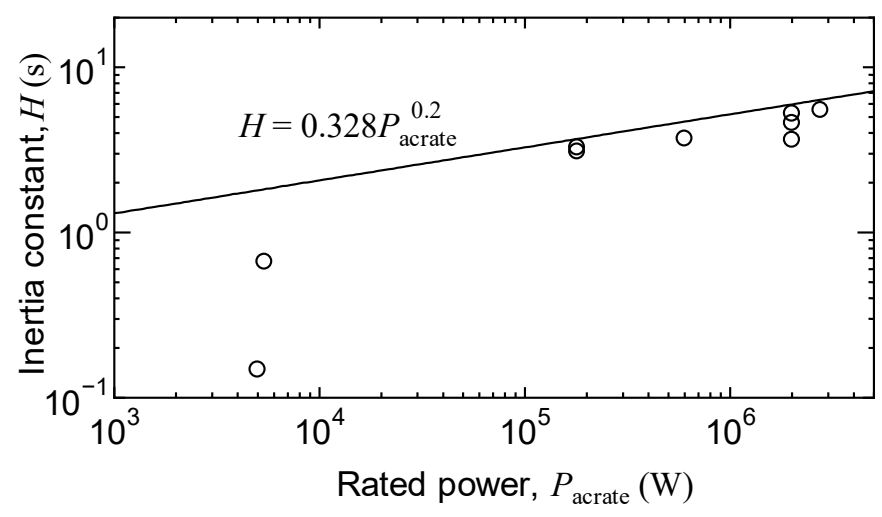

Figure 3. Relationship between rated value $P_{\text {acrate }}$ and inertia constant $H$ of HAWTs. 
Table 1. Practical parameters related to inertia constants of horizontal axis wind turbines (HAWTs).

\begin{tabular}{|c|c|c|c|c|c|c|c|}
\hline $\begin{array}{c}\text { Rated } \\
\text { Power } \\
P_{\text {acrate }}(W)\end{array}$ & $\begin{array}{c}\text { Turbine } \\
\text { Inertia } \\
J_{w t}\left(\mathrm{~kg} \cdot \mathrm{m}^{2}\right)\end{array}$ & $\begin{array}{c}\text { Generator } \\
\text { Inertia } \\
J_{\mathrm{g}}\left(\mathbf{k g} \cdot \mathrm{m}^{2}\right)\end{array}$ & $\begin{array}{c}\text { Gear } \\
\text { Ratio } \eta\end{array}$ & $\begin{array}{l}\text { Num. of Pole } \\
\text { Pairs } p\end{array}$ & $\begin{array}{c}\text { Freq. of } \\
\text { Generator } \\
\text { Voltage } 1 \\
f_{\text {erate }}(\mathrm{Hz})\end{array}$ & $\begin{array}{c}\text { Inertia } \\
\text { Constant } H\end{array}$ & Source \\
\hline $2.75 \times 10^{6}$ & $1.26 \times 10^{7}$ & 239 & 70.65 & 3 & 50 & 5.51 & [12] \\
\hline $2.0 \times 10^{6}$ & $6.41 \times 10^{6}$ & 121.5 & 93.75 & 2 & 50 & 5.25 & [13] \\
\hline $2.0 \times 10^{6}$ & $4.18 \times 10^{6}$ & 93.22 & 80 & 2 & 50 & 4.60 & [14] \\
\hline $2.0 \times 10^{6}$ & \multicolumn{2}{|c|}{$J_{\mathrm{tot}}=5.90 \times 10^{6}$} & 100 & 2 & 50 & 3.64 & [15] \\
\hline $6.0 \times 10^{5}$ & $4.54 \times 10^{5}$ & 30 & 55 & 2 & 50 & 3.70 & [16] \\
\hline $1.8 \times 10^{5}$ & $5.80 \times 10^{4}$ & 4.5 & 23.75 & 3 & 50 & 3.27 & [17] \\
\hline $1.8 \times 10^{5}$ & $5.55 \times 10^{4}$ & 3.19 & 23.75 & 3 & 50 & 3.09 & [18] \\
\hline $5.4 \times 10^{3}$ & 5.83 & 0.25 & 5 & 8 & 155.33 & 0.67 & {$[19]^{2}$} \\
\hline $5.0 \times 10^{3}$ & \multicolumn{2}{|c|}{$J_{\text {tot }}=6$} & 1 & 20 & 50 & 0.15 & {$[20]^{3}$} \\
\hline
\end{tabular}

${ }^{1}$ Synchronous frequency is described for asynchronous generators connected to a grid without a PCS. ${ }^{2}$ Several parameters were obtained by private communication with Dr. S. Aoki and a manufacturer. ${ }^{3} J_{\text {tot }}$ was confirmed by private communication with Prof. M. Malinowski.

$$
H \cong 0.328 P_{\text {acrate }}^{0.2}
$$

Although the empirical equations in [21] are intended for applications to MW-class wind turbines, an attempt was made to apply Equation (3) to SWTs in Figure 3, as achieved in [22]. Figure 3 indicates that the practical inertia constants $H$ of the large-scale wind turbines are slightly lower than the values estimated by Equation (3), and those of the SWTs are significantly lower. Moreover, Table 1 and Figure 3 indicate that the inertia constants $H$ of SWTs are slightly lower than those of the large-scale wind turbines. The statement above, in addition to Equation (2), indicates that the rotor angular velocity $\omega_{\mathrm{m}}$ exhibits a higher acceleration in SWTs during the FRT operation.

\section{FRT Test of 5-kW SWT}

\subsection{Specification and Configuration of the SWT System}

The FRT tests were conducted at the field test site established to obtain and verify various types of operational data of SWT systems, as a part of the New Energy and Industrial Technology Development Organization (NEDO) project at the seaside of reclaimed land for the Toyokawa Water Purification Center in Shin-Nishihama, Toyohashi, Aichi, Japan. The final target of the project was a 30\% total cost reduction of SWT systems. One of the SWT systems tested at the site was a 5-kW horizontal-axis SWT system developed as a part of the project, with the specifications presented in Table 2. The system has a similar configuration to that shown in Figure 1. Moreover, a furling mechanism was adopted for overspeed suppression. However, the automatic furling control was still in the process of development; thus, the tilt angle of the rotational axis was occasionally controlled by manual input to the control personal computer (PC). In particular, the tilt angle was kept constant during the FRT tests, given that the operability was significantly low; thus, the control action could not be carried out within the short test periods. The SWT system used a 5.8-kW, 100/200-V single-phase three-wire PCS (Enewell-WIN) manufactured by the Yaskawa Electric Corporation.

Table 2. Specification of the 5-kW horizontal-axis small wind turbines (SWT) [19]. Parameters related to inertia are described in Table 1.

\begin{tabular}{cccccc}
\hline $\begin{array}{c}\text { Rotor } \\
\text { Diameter 2R }\end{array}$ & Rated Power & Hub Height & $\begin{array}{c}\text { Turbine Rated } \\
\text { Speed } \omega_{\text {mrate }}\end{array}$ & Gear Ratio $\eta$ & $\begin{array}{c}\text { Tip-Speed } \\
\text { Ratio } \lambda_{\text {opt }}\end{array}$ \\
\hline $5.4 \mathrm{~m}$ & $5.4 \mathrm{~kW}$ & $12 \mathrm{~m}$ & $233 \mathrm{rpm}$ & 5 & 6 \\
\hline
\end{tabular}




\subsection{Configuration of the Test System}

A programmable AC power source (DP090RS, NF Corporation) was connected to the AC terminal of the PCS, instead of the power grid. The AC power source was set to generate a voltage with a sinusoidal waveform of $202 \mathrm{~V}$ and $60 \mathrm{~Hz}$ under normal conditions, and to simulate the voltage dip with the programmed magnitude and duration. Neutral potential was generated by the resistive division of the voltage, and then connected to the neutral line; which the PCS uses only for the monitoring voltage, and through which no current flows. No circuit element to simulate distribution line impedance was incorporated according to the corresponding certification test procedure published by the certification institution on PCSs for small distributed PV systems in Japan [23] (p.10). Although the power source can operate with bi-directional (output and input) power, the capacity of the power consumption is limited. Thus, a resistor with an automatic load control function was connected in parallel to reduce the power consumption of the power source to an acceptable level [24].

With respect to instantaneous measurements, the voltage and current of the PCS DC input $\left(V_{\mathrm{dc}}\right.$, $\left.I_{\mathrm{dc}}\right)$ and AC output $\left(V_{\mathrm{ac}}, I_{\mathrm{ac}}\right)$ were measured using a digital storage oscilloscope (DL850, Yokogawa), and then the active power output $P_{\mathrm{ac}}$ and root mean square (RMS) values of $V_{\mathrm{ac}}$ and $I_{\mathrm{ac}}$ were calculated. The AC terminal voltage of the synchronous generator was measured using the oscilloscope to monitor the frequency $f_{\mathrm{e}}$, and then it was converted to the angular velocity of the turbine as $\omega_{\mathrm{m}}=2 \pi f_{\mathrm{e}} /(\eta p)$.

With respect to the wind speed measurement, an anemometer (Class 1, NRG Systems) was set at the hub height, and the output signal was recorded every at intervals of $0.1 \mathrm{~s}$ using a data logger. The data logger also recorded the analog output signal of a clamp-on power meter (3169, Hioki) that was used to measure the PCS output power $P_{\mathrm{ac}}$. By super-imposing variations of the PCS output power $P_{\text {ac }}$ measured using the oscilloscope and the data logger, the wind speed during the FRT test was determined.

\subsection{Test Result}

In the JEAC Grid-Interconnection Code, which is a part of the grid code in Japan, PV power systems connected to low-voltage distribution lines are required to remain connected during a voltage dip with a residual magnitude of $\geq 20 \%$ and a duration of $\leq 1 \mathrm{~s}$. In addition, within $0.1 \mathrm{~s}$ after the recovery of the $A C$ voltage, they are required to recover the output power until $\geq 80 \%$ of the power immediately before the dip occurs [25] (p. 69). There is no requirement on reactive power output for voltage support during a voltage dip.

In this study, a severer condition than the Grid Code was chosen for FRT tests. Figure 4 presents a test result in the case of a voltage dip with a residual magnitude of zero and a duration of $1.0 \mathrm{~s}$. Figure 4 indicates that the PCS output power $P_{\text {ac }}$ recovered rapidly (with a delay of approximately one cycle) after the recovery of the AC voltage. In addition, the gate block signal was not detected in the PCS during the test. Hence, the SWT system satisfied the FRT requirements for PV systems connected to low-voltage distribution lines.

The performance of the system during the test can be described as follows. The PCS output power $P_{\text {ac }}$ was $3.7 \mathrm{~kW}$, and the turbine angular velocity $\omega_{\mathrm{m}}$ was almost constant before the voltage dip, which implies that the mechanical input power $P_{\mathrm{m}}$ was approximately $3.7 \mathrm{~kW}$, according to Equation (2). However, the $P_{\text {ac }}$ reduced to zero at time $t=0$ due to the voltage dip, and turbine angular velocity $\omega_{\mathrm{m}}$ increased in accordance with Equation (2), where $P_{\mathrm{m}}$ had no drastic variation (strictly, $P_{\mathrm{m}}$ was estimated to be gradually reduced due to the deviation of $\lambda\left(=R \omega_{\mathrm{m}} / v_{\mathrm{W}}\right)$ from $\lambda_{\mathrm{opt}}$, given that the wind speed $v_{\mathrm{w}}$ did not exhibit significant variations). After the recovery of AC terminal voltage $V_{\mathrm{ac}}$ of the PCS at around $t=1 \mathrm{~s}$, the PCS generated active power $P_{\mathrm{ac}}$ again. At this time, $P_{\mathrm{ac}}$ reached the rated output power of the PCS $(5.8 \mathrm{~kW})$, given that the PCS input voltage $V_{\mathrm{dc}}$ was higher than $V_{\mathrm{dcrate}}$ due to $\omega_{\mathrm{m}}>\omega_{\text {mrate, }}$ and that $P_{\text {ac }}$ was controlled in accordance with Figure 2 for the MPPT. Hence, the turbine angular velocity $\omega_{\mathrm{m}}$ decreased in accordance with Equation (2), and finally returned to the initial speed prior to the voltage dip at $t \simeq 4 \mathrm{~s}$. 


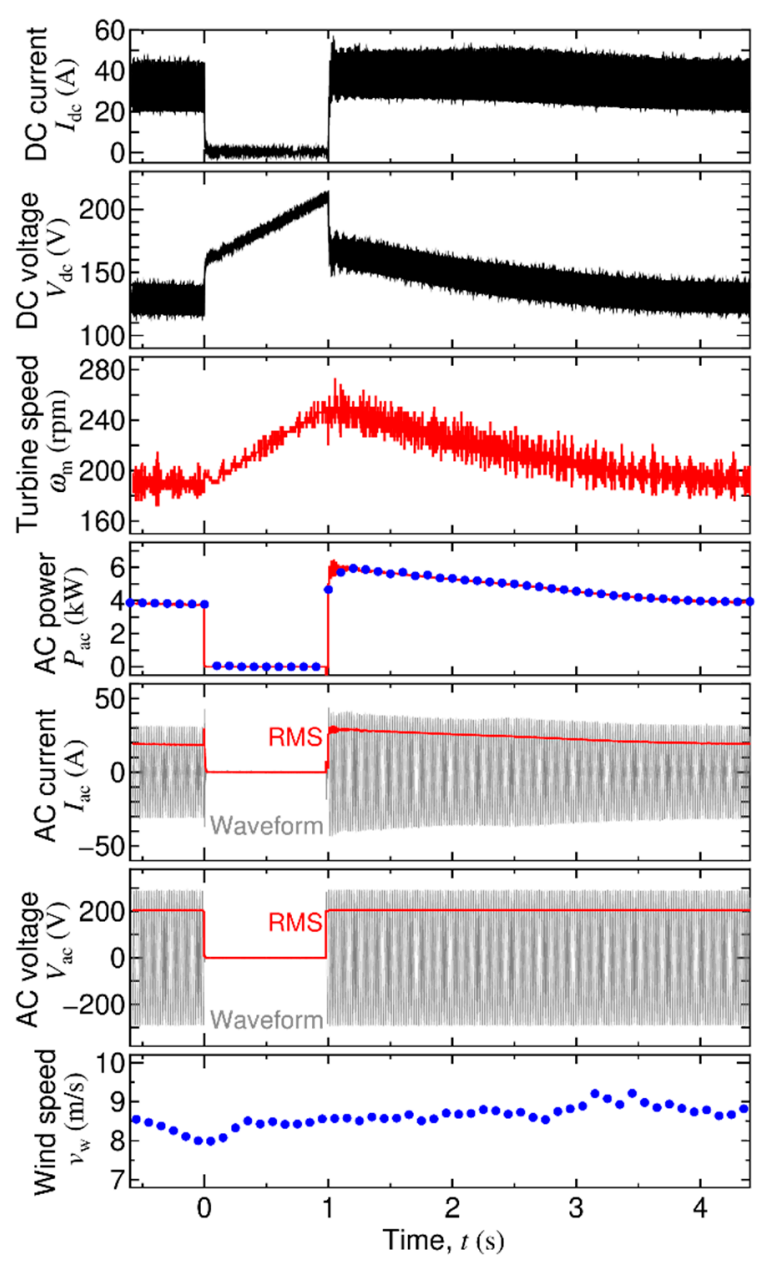

(a)

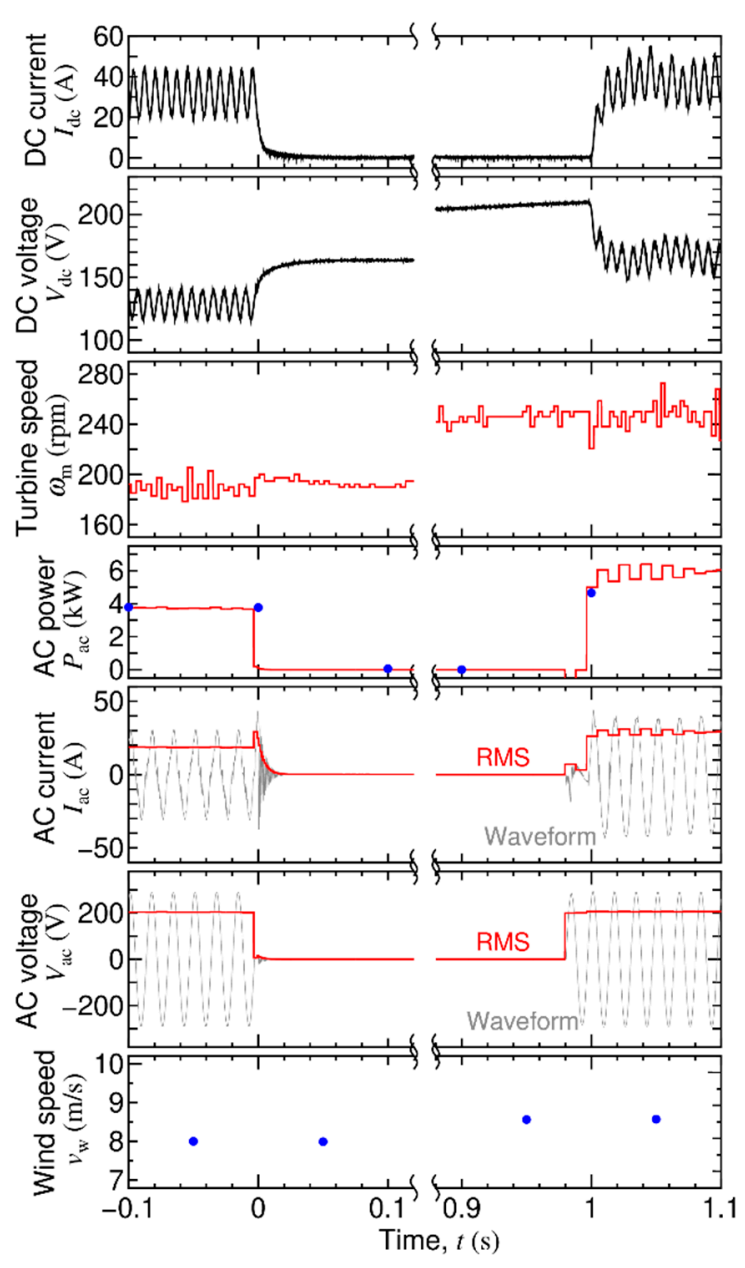

(b)

Figure 4. Time variation at a fault ride-through (FRT) test on 5.4-kW horizontal-axis small wind turbine system. The red-colored curves represent the signal derived from the raw data obtained using the oscilloscope, and the blue-colored dots represent the data obtained using the data logger. (a) Description of entire test period; and (b) enlarged at the start and end of the voltage dip.

During the voltage dip, AC current $I_{\mathrm{ac}}$ was reduced to zero, which means that not only active power but also reactive power were not generated by the PCS. This is of no importance because reactive power output for voltage support is not required on the small-scale dispersed generators connected to low-voltage distribution systems in the Japanese grid code.

In Figure $4 \mathrm{a}$, pulsations were observed in the PCS input voltage $V_{\mathrm{dc}}$ and current $I_{\mathrm{dc}}$ when $P_{\mathrm{ac}}>0$, and Figure $4 \mathrm{~b}$ indicates that the frequency of the pulsations was $120 \mathrm{~Hz}$. They were due to the cyclic output of instantaneous power to the $60-\mathrm{Hz}$ AC grid, which is a typical characteristic of single-phase inverters.

\subsection{Discussion}

The performances of the PCS input voltage and current $\left(V_{\mathrm{dc}}\right.$ and $\left.I_{\mathrm{dc}}\right)$ of the SWT system in an FRT operation are described in this section, in comparison with a typical PV system.

Figure 5a presents typical $I_{\mathrm{dc}}-V_{\mathrm{dc}}$ curves of a PV array connected to a PCS in a PV system, with several cases of respective solar irradiance values, numerically simulated by using the equations and parameters in [26]. The PCS input voltage $V_{\mathrm{dc}}$ is adjusted to maximize $I_{\mathrm{dc}} V_{\mathrm{dc}}$, which is referred to the MPPT control, under normal operating conditions. In the case of the solar irradiance of $1000 \mathrm{~W}$, as shown in Figure $5 \mathrm{a}$, the point $\mathrm{A}^{\prime}$ at $V_{\mathrm{dc}}=160 \mathrm{~V}$ is the maximum power point (MPP) on the curve. 
Upon the occurrence of a voltage dip with a residual magnitude of zero, as discussed in Section 3.3, the PCS output power $P_{\mathrm{ac}}$ is reduced to zero; thus, the PCS input power $I_{\mathrm{dc}} V_{\mathrm{dc}}$ is also reduced to zero by reducing the PCS input current $I_{\mathrm{dc}}$ to zero. Consequently, the PCS input voltage $V_{\mathrm{dc}}$ increases to an open-circuit voltage of $200 \mathrm{~V}$, which implies that the operational point shifts from $\mathrm{A}^{\prime}$ to $\mathrm{B}^{\prime}$ along the curve. There are no significant changes during the voltage dip, which has a duration of $\sim 1 \mathrm{~s}$. After the recovery of the AC voltage $V_{\mathrm{ac}}$, the PCS output power $P_{\mathrm{ac}}$ is rapidly recovered by decreasing $V_{\mathrm{dc}}$ to the MPP voltage with the control of the power electronic interface in the PCS, which indicates that the operational point re-shifts from $\mathrm{B}^{\prime}$ to $\mathrm{A}^{\prime}$. Such an operation is attained generally by PCSs for residential PV systems in Japan.

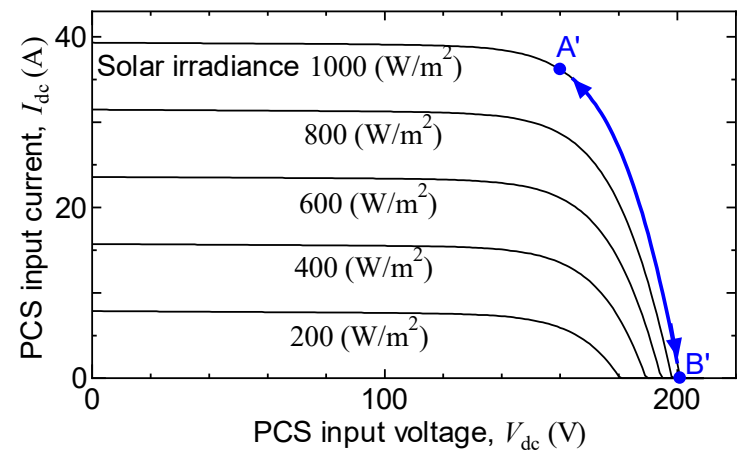

(a)

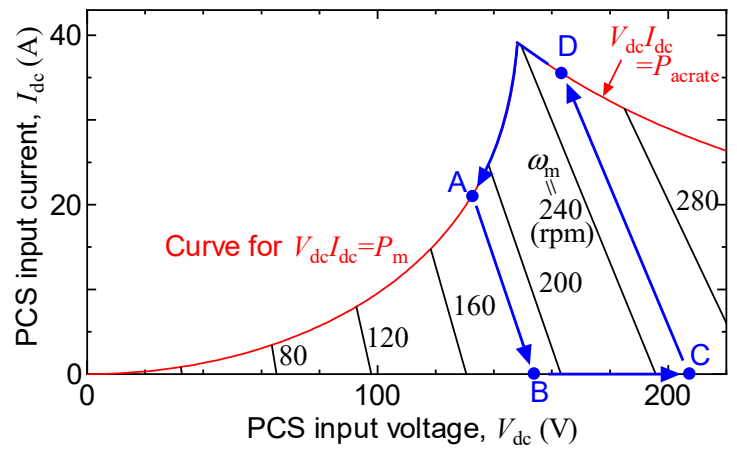

(b)

Figure 5. Simulated $I_{\mathrm{dc}}-V_{\mathrm{dc}}$ characteristics of (a) photovoltaic (PV) power system and (b) SWT system. The blue-colored points indicate the variations of the operational points of PCSs at an FRT against an AC side voltage dip.

Figure $5 \mathrm{~b}$ presents the $I_{\mathrm{dc}}-V_{\mathrm{dc}}$ characteristics of the SWT system numerically simulated while adjusting parameters to fit the test result in Figure 4 under the following conditions:

- The mechanical input power $P_{\mathrm{m}}$ is proportional to the cube of turbine angular velocity $\omega_{\mathrm{m}}$, as described in Section 2.2, until $P_{\mathrm{m}}$ reaches $P_{\text {acrate }}$.

- $\quad$ Losses in the synchronous generator, rectifier, and PCS are neglected $\left(P_{\mathrm{m}}=V_{\mathrm{dc}} I_{\mathrm{dc}}=P_{\mathrm{ac}}\right)$.

- The input side circuit (including the synchronous generator and the rectifier), which is connected to the input terminal of the PCS, is replaced by a Thevenin equivalent circuit that consists of an equivalent voltage source $V_{\text {th }}$ connected in series with an equivalent impedance $Z_{\text {th }}$.

- The equivalent voltage source $V_{\mathrm{th}}$, which is $V_{\mathrm{dc}}$ at $I_{\mathrm{dc}}=0$, is proportional to $f_{\mathrm{e}}\left(\propto \omega_{\mathrm{m}}\right)$, as the induced voltage of the synchronous generator.

- The equivalent impedance is represented by $Z_{\mathrm{th}} \equiv \sqrt{R_{\mathrm{th}}^{2}+\left(2 \pi f_{\mathrm{e}} L_{\mathrm{th}}\right)^{2}}$, where $R_{\mathrm{th}}$ and $L_{\mathrm{th}}$ are related to the armature resistance and synchronous inductance of the synchronous generator, respectively.

In Figure $5 \mathrm{~b}$, the black-colored lines represent the equation $V_{\mathrm{dc}}=V_{\mathrm{th}}-Z_{\mathrm{th}} I_{\mathrm{dc}}$ in several cases of the respective turbine angular velocity $\omega_{\mathrm{m}}$. The red-colored curve represents the operational points for the conversion of all the mechanical input power into electrical output power $\left(V_{\mathrm{dc}} I_{\mathrm{dc}}=P_{\mathrm{m}}\right)$ when $P_{\mathrm{m}}<P_{\text {acrate}}$, or for fixed output at the rated power $\left(V_{\mathrm{dc}} I_{\mathrm{dc}}=P_{\text {acrate }}\right)$ when $P_{\mathrm{m}} \geq P_{\text {acrate }}$.

The trends of the PCS input voltage and current $\left(V_{\mathrm{dc}}\right.$ and $\left.I_{\mathrm{dc}}\right)$ of the SWT system in the FRT test, as described in Section 3.3, can be explained with reference to Figure 5b, as follows. First, the PCS was operated at point A with $V_{\mathrm{dc}} \simeq 130 \mathrm{~V}$ and $\omega_{\mathrm{m}} \simeq 190 \mathrm{rpm}$ immediately prior to the voltage dip. Thereafter, there was a voltage dip with a residual magnitude of zero, which made the PCS output power $P_{\text {ac }}$ zero. Thus, the operational point shifted from A to B, where the PCS input current $I_{\mathrm{dc}}$ was reduced to zero; and consequently, the PCS input voltage $V_{\mathrm{dc}}$ increased to an open-circuit voltage of approximately $160 \mathrm{~V}$, along the line of $\omega_{\mathrm{m}} \simeq 190 \mathrm{rpm}$. The turbine angular velocity $\omega_{\mathrm{m}}$ then increased, and it reached $\sim 250 \mathrm{rpm}$ during the voltage dip, which indicates that the operational point shifted 
from $B$ to $C$ with an open-circuit voltage of approximately $210 \mathrm{~V}$. After the recovery of the AC terminal voltage $V_{\text {ac }}$, the PCS re-generated active power $P_{\text {ac }}$; the operational point shifted from $C$ to $\mathrm{D}$ along the line of $\omega_{\mathrm{m}} \simeq 250 \mathrm{rpm}$. Finally, at a constant wind speed $v_{\mathrm{w}}$, the angular velocity $\omega_{\mathrm{m}}$ of the turbine gradually reduced in accordance with Equation (2), due to $P_{\mathrm{ac}}>P_{\mathrm{m}}$, and then the operational point re-shifted from $\mathrm{D}$ to A along the curve of $P_{\mathrm{m}}$.

When the performance of the SWT system was compared with that of the PV system, the variations of the operational points from $A$ to $B$ and from $C$ to $D$ in the SWT system were similar to those from $\mathrm{A}^{\prime}$ to $\mathrm{B}^{\prime}$ and from $\mathrm{B}^{\prime}$ to $\mathrm{A}^{\prime}$ in the PV system, respectively. However, the variations from $\mathrm{B}$ to $\mathrm{C}$ and from $D$ to A with respect to change of the turbine angular velocity $\omega_{m}$ in the SWT system are notable. In particular, the variation from B to $C$ implies an increase in the PCS input voltage $V_{\mathrm{dc}}$. If the wind speed $v_{\mathrm{w}}$ was higher than that in the test condition, as discussed in Section 3.3, the PCS input voltage $V_{\mathrm{dc}}$ at all points A, B, C, and D would be higher. Moreover, in such a case, $V_{\mathrm{dc}}$ should be prevented from reaching the upper limit of the PCS. If not, the PCS operation would stop, as the result of a self-protection mechanism, which would result in the failure of the FRT. The overvoltage should be restricted using other methods (except PCS), such as pitch control and furling, in addition to the implementation of electrical and/or mechanical brakes, because it is difficult to employ dump resistors in parallel with the DC-link capacitor in the PCS for SWT owing to commercial issues, as described in Section 2.

\section{FRT Test of 1-kW SWTs}

The other SWT system tested at the field test site was a system with two 1-kW SWTs. The specifications of the SWTs, HAWT, and a vertical-axis wind turbine (VAWT) are shown in Table 3. They were commercial SWTs manufactured by private companies, and the parameters related to the inertia constants and braking resistors were not published.

Table 3. Specification of 1-kW SWTs.

\begin{tabular}{|c|c|c|c|c|c|}
\hline Model & Manufacturer & Type & $\begin{array}{l}\text { Output } \\
(11 \mathrm{~m} / \mathrm{s})\end{array}$ & $\begin{array}{c}\text { Rated DC } \\
\text { Voltage }\end{array}$ & Over Speed Limiter \\
\hline Airdolphin GTO Z-1000-250 [27] & Zephyr & 3-bladed horizontal axis & $0.7 \mathrm{~kW}$ & $260 \mathrm{~V}$ & Braking resistors \\
\hline Kharios N1000-BGG [28] & Nakanishi Metal Works & 4-bladed vertical axis & $1 \mathrm{~kW}$ & $290 \mathrm{~V}$ & Braking resistors \\
\hline
\end{tabular}

The SWTs were connected to a multistring PCS. A multistring PCS consists of several DC-DC converters and an inverter with a common DC link. It is typically used for PV systems with different PV string characteristics (different orientations and/or different degrees of shading), as it can significantly increase the system efficiency due to the availability of MPPT control in respective strings [29].

The programmable AC power source DP090RS was connected to the AC terminal of the PCS and used to simulate a voltage dip with a programmed magnitude and duration, as described in Section 3.2. The wind speed $v_{\mathrm{w}}$ was also measured in the same manner as described in Section 3.2. The voltage and current of the PCS DC input $\left(V_{\mathrm{dc}}, I_{\mathrm{dc}}\right)$ and AC output $\left(V_{\mathrm{ac}}, I_{\mathrm{ac}}\right)$ were measured using the digital storage oscilloscope; however, the $I_{\mathrm{dc}}$ of the VAWT and frequency $f_{\mathrm{e}}$ of the SWTs were not measured, due to the limit of the channel number in the oscilloscope. Figure 6 presents the test results for the case of a voltage dip with a residual magnitude of $20 \%$ and a duration of $0.9 \mathrm{~s}$. Figure 6 indicates that the PCS output power $P_{\mathrm{ac}}$ was recovered rapidly after the recovery of the AC voltage, which is in accordance with the test results of the 5-kW SWT system, as described in Section 3.3. In addition, the gate block signal was not detected in the PCS during the test. The results presented above confirm that the SWT system with the 1-kW SWTs satisfied the FRT requirements for PV systems connected to low-voltage distribution lines. 


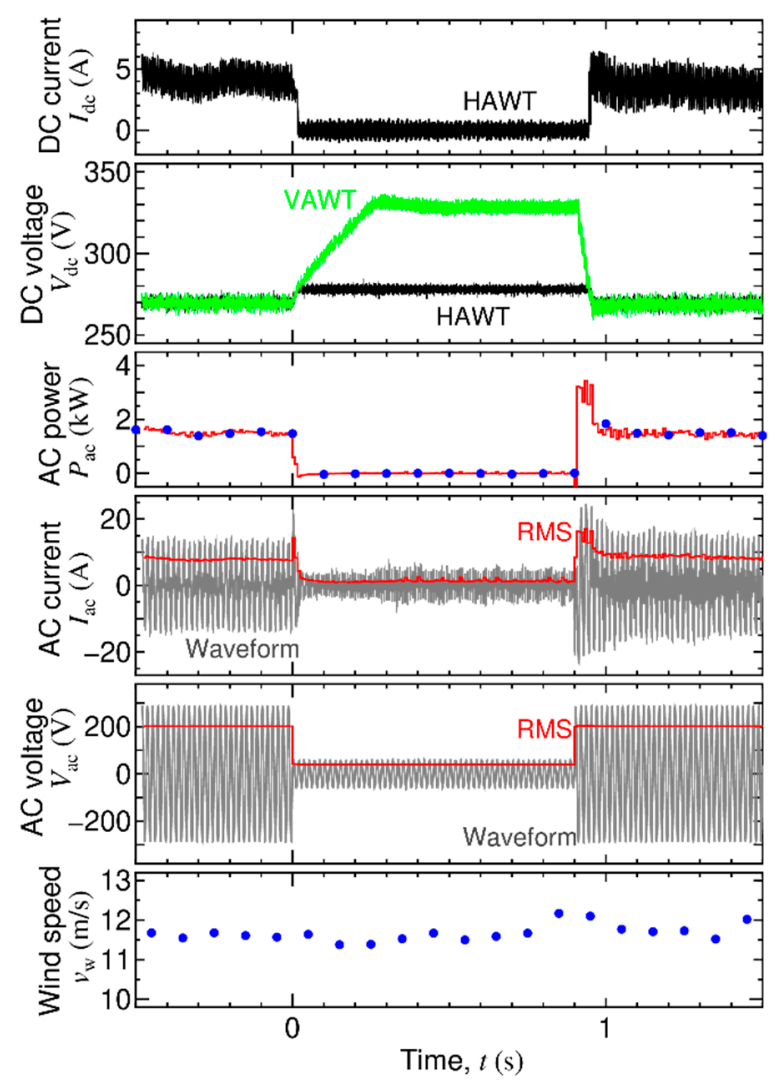

Figure 6. Wind speed, AC voltage, current and power, and DC voltage and current with respect to time for an FRT test conducted on two 1-kW small wind turbines. The red-colored curves indicate the data processed from the raw data obtained using the oscilloscope, and the blue-colored dots indicate the data obtained using the data logger.

The performance of the system during the test can be described as follows. The PCS output power $P_{\mathrm{ac}}$ was $1.5 \mathrm{~kW}$ prior to the voltage dip, which indicates that the mechanical input power $P_{\mathrm{m}}$ was approximately $1.5 \mathrm{~kW}$, according to Equation (2). However, $P_{\text {ac }}$ reduced to zero at time $t=0$ due to the voltage dip, and the turbine angular velocity $\omega_{\mathrm{m}}$ of the HAWT and VAWT increased, in accordance with Equation (2), where $P_{\mathrm{m}}$ had no drastic variation (strictly, $P_{\mathrm{m}}$ was estimated to be gradually reduced due to the deviation of $\lambda\left(=R \omega_{\mathrm{m}} / v_{\mathrm{w}}\right)$ from $\lambda_{\mathrm{opt}}$, given that no significant variations in the wind speed $v_{\mathrm{w}}$ were observed). However, the increases in the turbine angular velocity $\omega_{\mathrm{m}}$ and the DC voltage $V_{\mathrm{dc}}$ were restricted by the use of the electrical brakes: from $t \simeq 0.02 \mathrm{~s}$ in the HAWT, and from $t \simeq 0.27 \mathrm{~s}$ in the VAWT. Because the variation in $V_{\mathrm{dc}}$ was small in the HAWT, regardless of the voltage dip, power consumption in the electrical brake during the voltage dip was estimated to be almost the same as $P_{\mathrm{dc}}\left(=V_{\mathrm{dc}} I_{\mathrm{dc}}\right)$ before the voltage dip. Thus, the current in the electrical brake during the voltage dip was estimated to be almost the same as $I_{\mathrm{dc}}$ before the voltage dip in the HAWT, although it was not measured owing to the limited number of channels in the oscilloscope. After the recovery of AC terminal voltage $V_{\mathrm{ac}}$ of the PCS at $t=0.9 \mathrm{~s}$, the PCS re-generated active power $P_{\mathrm{ac}}$. From this time until $t \simeq 0.95 \mathrm{~s}, P_{\text {ac }}$ was higher than that its value immediately prior to the voltage dip, due to the $P_{\mathrm{ac}}-V_{\mathrm{dc}}$ characteristic of the MPPT, as shown in Figure 2. Finally, the DC voltage $V_{\mathrm{dc}}$ decreased to its initial value prior to the voltage dip. The duration of the excess power output was significantly shorter than that in the case of the 5-kW SWT system, as described in Section 3.3, which is due to the energy dissipation in the electrical brakes during the voltage dip.

During the voltage dip, the RMS value of AC current $I_{\mathrm{ac}}$ decreased to $\sim 1 \mathrm{~A}$, including high magnitudes of harmonics, which means proper reactive power was not generated by the PCS. This is not important because reactive power output for voltage support is not required on the small-scale 
dispersed generators connected to low-voltage distribution systems in the Japanese grid code, as described in Section 3.3.

\section{Conclusions}

Whereas the FRT of large-scale wind turbines has already been developed, the FRT of SWTs is still challenging to achieve because of the low inertia constants of SWTs in comparison with those of large-scale wind turbines, which results in significant acceleration of the rotor speed and increase in the PCS input voltage during FRT operation. In addition, commercial issues causing use of the same hardware as the kW-class PCSs for the mass-produced residential PV systems exist. In this study, FRT field tests were conducted on SWT systems against a voltage dip with a duration of $\sim 1 \mathrm{~s}$. As validated by the experimental results, the SWT systems satisfied the FRT requirements for PV systems connected to low-voltage distribution lines in Japan. The trends of the PCS input voltage and current of the SWT system in FRT operation were then analyzed and compared with those of a PV system. For high wind speeds, the increase of the PCS input voltage with the overspeed of the turbine can potentially reach the upper limit of the PCS, which results in the operation ceasing; that is, failure of the FRT. Therefore, in the case of SWT systems, the overvoltage should be restricted using any other methods (except PCS), such as pitch control, furling, and the implementation of electrical and/or mechanical brakes.

Author Contributions: The main roles of the authors were as follows. J.K. was in charge of supervision, project administration, investigation, and the preparation of the manuscript; H.M. led and conducted the FRT tests and wrote a draft in Japanese; and T.F. provided support to the aforementioned authors.

Funding: This research was funded in part by the New Energy and Industrial Technology Development Organization (NEDO).

Acknowledgments: This paper is based on results obtained from a project commissioned by the New Energy and Industrial Technology Development Organization (NEDO). The authors would like to acknowledge the support from the researchers and students at the National Institute of Advanced Industrial Science and Technology (AIST), in addition to Toyohashi University of Technology (TUT), who operated the 5-kW SWT during the experiments. The authors would also like to acknowledge the respective officials in Toyohashi City who supported the installation of the test site. Furthermore, the authors would like to thank M. Kubo in Sylphid Inc. and H. Shinohara in Japan Electrical Safety \& Environment Technology Laboratories (JET) for the helpful discussion related to Figure $5 b$.

Conflicts of Interest: The authors declare no conflict of interest.

\section{References}

1. Li, Y.; Gao, W.; Ruan, Y. Performance investigation of grid-connected residential PV-battery system focusing on enhancing self-consumption and peak shaving in Kyushu, Japan. Renew. Energy 2018, 127, 514-523. [CrossRef]

2. Li, Y.; Gao, W.; Ruan, Y. Quantifying variabilities and impacts of massive photovoltaic integration in public power systems with PHS based on real measured data of Kyushu, Japan. Energy Procedia 2018, 152, 883-888. [CrossRef]

3. IEA Wind TCP, 2015 Annual Report. 30 Japan. pp. 160-165. Available online: https://community.ieawind. org/publications/ar (accessed on 29 November 2019).

4. GWEC. Global Wind Report. Annual Market Update 2017. p. 50. Available online: https://gwec.net/ publications/global-wind-report-2/ (accessed on 29 November 2019).

5. Ogimoto, K.; Kaizuka, I.; Ueda, Y.; Oozeki, T. A Good Fit: Japan's Solar Power Program and Prospects for the New Power System. IEEE Power Energy Mag. 2013, 11, 65-74. [CrossRef]

6. Ding, G.; Gao, F.; Tian, H.; Ma, C.; Chen, M.; He, G.; Liu, Y. Adaptive DC-Link Voltage Control of Two-Stage Photovoltaic Inverter During Low Voltage Ride-Through Operation. IEEE Trans. Power Electron. 2016, 31, 4182-4194. [CrossRef]

7. Conroy, J.F.; Watson, R. Low-voltage ride-through of a full converter wind turbine with permanent magnet generator. IET Renew. Power Gener. 2007, 1, 182-189. [CrossRef]

8. Yang, L.; Xu, Z.; Østergaard, J.; Dong, Z.Y.; Wong, K.P. Advanced Control Strategy of DFIG Wind Turbines for Power System Fault Ride Through. IEEE Trans. Power Syst. 2012, 27, 713-722. [CrossRef] 
9. Benbouzid, M.; Beltran, B.; Amirat, Y.; Yao, G.; Han, J.; Mangel, H. Second-order sliding mode control for DFIG-based wind turbines fault ride-through capability enhancement. ISA Trans. 2014, 53, 827-833. [CrossRef] [PubMed]

10. Wood, D. Small Wind Turbines; Springer: London, UK, 2011; pp. 4-19.

11. Hansen, A.D.; Michalke, G. Multi-pole permanent magnet synchronous generator wind turbines' grid support capability in uninterrupted operation during grid faults. IET Renew. Power Gener. 2009, 3, 333-348. [CrossRef]

12. van der Hooft, E.L.; Schaak, P.; van Engelen, T.G. Wind turbine control algorithms; Netherlands Energy Research Foundation ECN: Petten, The Netherlands, 2013; pp. 1-94.

13. Knudsen, H.; Nielsen, J.N. Introduction to the Modelling of Wind Turbines. In Wind Power in Power Systems, 2nd ed.; Ackermann, T., Ed.; John Wiley \& Sons: Chichester, UK, 2012; pp. 769-797.

14. Sørensen, P.E.; Hansen, A.D.; Christensen, P.; Mieritz, M.; Bech, J.; Bak-Jensen, B.; Nielsen, H. Simulation and Verification of Transient Events in Large Wind Power Installations; Forskningscenter Risø: Roskilde, Denmark, 2003; Risø-R-1331(EN).

15. Slootweg, J.G.; Polinder, H.; Kling, W.L. Dynamic modelling of a wind turbine with doubly fed induction generator. In Proceedings of the 2001 IEEE PES Summer Meeting, Vancouver, BC, Canada, 15-19 July 2001; pp. 644-649.

16. Salman, S.K.; Teo, A.L.J. Windmill modeling consideration and factors influencing the stability of a grid-connected wind power-based embedded generator. IEEE Trans. Power Syst. 2003, 18, 793-802. [CrossRef]

17. Petru, T.; Thiringer, T. Modeling of Wind Turbines for Power System Studies. IEEE Trans. Power Syst. 2002, 17, 1132-1139. [CrossRef]

18. Rasila, M. Torque- and Speed Control of a Pitch Regulated Wind Turbine. Master's Thesis, Chalmers University of Technology, Göteborg, Sweden, 2003.

19. Aoki, S.; Kogaki, T.; Sakurai, K. Construction of the aero-elastic simulation model (AIST-RAM) for Horizontal Axis Small Wind Turbine. J. JWEA 2017, 41, 40-47. (In Japanese)

20. Kot, R.; Rolak, M.; Malinowski, M. Comparison of maximum peak power tracking algorithms for a small wind turbine. Math. Comput. Simul. 2013, 91, 29-40. [CrossRef]

21. Morren, J.; Pierik, J.; de Haan, S.W.H. Inertial response of variable speed wind turbines. Electr. Power Syst. Res. 2006, 76, 980-987. [CrossRef]

22. Engleitner, R.; Nied, A.; Cavalca, M.S.M.; da Costa, J.P. Dynamic Analysis of Small Wind Turbines Frequency Support Capability in a Low-Power Wind-Diesel Microgrid. IEEE Trans. Ind. Appl. 2018, 54, 102-111. [CrossRef]

23. Japan Electrical Safety \& Environment Technology Laboratories. Individual Test Method of Grid-Connected Protective Equipment etc. for Multi-Unit Grid-Connected PV Power Generating Systems, JET GR 0003-4-3.0; Japan Electrical Safety \& Environment Technology Laboratories: Japan, 2014. (In Japanese)

24. Funamoto, T.; Matsumoto, K.; Mizuno, H.; Tuyen, N.D.; Kondoh, J. Development of an FRT test system for a small wind turbine on real field (1) A resistor with automatic load control. Natl. Conv. Rec. IEE Jpn. 2016, 7-072, 105-106. (In Japanese)

25. Specialized sectional committee regarding Grid Interconnection. Grid-Interconnection Code. JEAC 9701-2012; The Japan Electric Association: Tokyo, Japan, 2013. (In Japanese)

26. Ikeno, T.; Utsumi, A.; Hirachi, K.; Nakagawa, S. MPPT method based on I-V characteristics Estimation by equivalent circuit model of PV module. IEEJ Trans. Power Energy 2018, 138, 514-520. (In Japanese) [CrossRef]

27. Airdolphin GTO. Available online: https://www.zephyreco.co.jp/en/products/airdolphin_gto.jsp (accessed on 20 September 2019).

28. The Compact Wind Turbine Generator. Available online: https://www.power-generator.jp/en/product/wind power/n1000.html (accessed on 20 September 2019).

29. Kwon, J.M.; Kwon, B.H.; Nam, K.H. Grid-Connected Photovoltaic Multistring PCS with PV Current Variation Reduction Control. IEEE Trans. Ind. Electron. 2009, 56, 4381-4388. [CrossRef] 